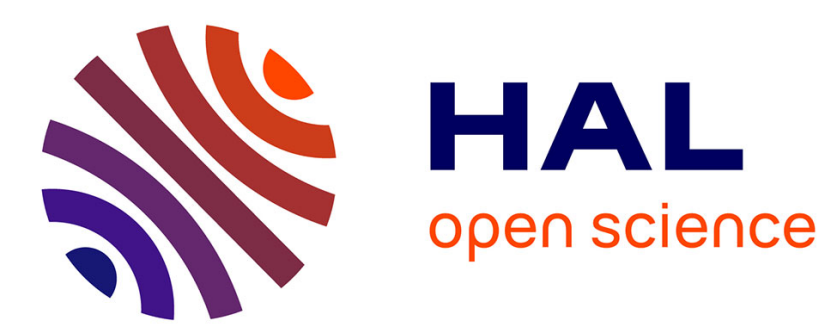

\title{
Development and characterization of a catalyst for the decomposition of hydrogen peroxide
}

Santiago Casu, Bastian Geiger, Rainer Kiemel, Jean-Yves Lestrade, Jérome Anthoine

\section{- To cite this version:}

Santiago Casu, Bastian Geiger, Rainer Kiemel, Jean-Yves Lestrade, Jérome Anthoine. Development and characterization of a catalyst for the decomposition of hydrogen peroxide. AIAA Propulsion and Energy 2019 Forum, Aug 2019, Indianapolis, United States. 10.2514/6.2019-4278 . hal-02320354

\section{HAL Id: hal-02320354 \\ https://hal.science/hal-02320354}

Submitted on 18 Oct 2019

HAL is a multi-disciplinary open access archive for the deposit and dissemination of scientific research documents, whether they are published or not. The documents may come from teaching and research institutions in France or abroad, or from public or private research centers.
L'archive ouverte pluridisciplinaire HAL, est destinée au dépôt et à la diffusion de documents scientifiques de niveau recherche, publiés ou non, émanant des établissements d'enseignement et de recherche français ou étrangers, des laboratoires publics ou privés. 


\title{
Development and characterization of a catalyst for the decomposition of hydrogen peroxide
}

\author{
Santiago Casu ${ }^{1}$, Bastian Geiger ${ }^{2}$ and Rainer Kiemel ${ }^{3}$ \\ Heraeus Deutschland GmbH \& Co. KG, 63450 Hanau, Germany \\ Jean-Yves Lestrade ${ }^{4}$ and Jérome Anthoine ${ }^{5}$ \\ ONERA - The French Aerospace Lab, 31410 Mauzac, France
}

\begin{abstract}
The design of a reliable and effective catalytic bed with high and reproducible performance is one of the key steps during the development of a highly concentrated hydrogen peroxide thruster. The present paper focuses on the development and characterization of such a catalyst for the decomposition of hydrogen peroxide. A catalyst pre-screening performed by Heraeus on various precious metal-based catalysts supported on alumina granules showed that $\mathrm{Pt}$ is the most promising metal for the decomposition of $\mathrm{H}_{2} \mathrm{O}_{2}$. Some further investigations were carried out to study the influence of various preparation parameters on the catalytic activity of the Pt catalysts. The prepared catalysts were characterized with various technics (transmission electron microscopy, X-ray diffraction, specific surface area) to better understand the impact of the studied preparation parameters on the catalyst activity for hydrogen peroxide decomposition. Finally, some monopropellant firing tests were performed by ONERA using the most promising catalysts and this paper presents some of the results obtained in their test facility.
\end{abstract}

\section{Introduction}

Since the 1960's, most of the orbital propulsion hot gases thrusters are based on hydrazine as a storable propellant. Because of its very high toxicity, hydrazine was included in ECHA's candidate list in 2011 and might be prioritized for inclusion in Annex XIV of REACH at any time. Therefore, the search for less toxic or "green" alternatives for hydrazine has become of great interest in the past few years. The most promising substitutes for hydrazine, like ammonium dinitramide (AND) or hydroxylammonium nitrate (HAN) both show higher density impulses [1,2] but suffer from very high combustion temperatures and require extremely expensive alloys and manufacturing processes for the realization of the combustion chamber. Hydrogen peroxide $\left(\mathrm{H}_{2} \mathrm{O}_{2}\right)$ on the other hand does not suffer from this major drawback and is currently reconsidered as a promising green propellant for thruster applications. Hydrogen peroxide has a relatively low nominal propulsive performance compared to hydrazine [3] and highly concentrated hydrogen peroxide with high density must be used to improve the volume specific impulse. The most conventional catalyst for $\mathrm{H}_{2} \mathrm{O}_{2}$ decomposition is metallic silver, which suffer from two major drawbacks, namely temperature limitations and poisoning from the stabilizers used to prevent the self-decomposition of hydrogen peroxide. Many research activities have been performed in the past few years about the catalytic decomposition of $\mathrm{H}_{2} \mathrm{O}_{2}$ [4-7]. Precious metals as well as Mn oxides were extensively studied but no real consensus seems to emerge about the most active metal for this reaction [8-10]. As a producer of the hydrazine decomposition catalyst HKC12GA, Heraeus Deutschland GmbH \& Co. KG. has gained a lot of experience in the past 15 years in the field of catalysis applied to thruster technology. The renewed interest for $\mathrm{H}_{2} \mathrm{O}_{2}$ as a green propellant lead us to carry out some activity on the development of a precious metal-based catalyst for the decomposition of hydrogen peroxide. The present article illustrates the results of this development.

\footnotetext{
${ }^{1}$ R\&D Project Manager, Global Business Unit Heraeus Precious Metals, Innovation Chemicals Labs and Services.

${ }^{2}$ Head of Catalyst Production, Global Business Unit Heraeus Precious Metals, Production Catalyst

${ }^{3}$ Senior Expert, Global Business Unit Heraeus Precious Metals, Chemical Innovation and Product Management

${ }_{5}^{4}$ Research Scientist, Multi-Physic for Energetics Department (DMPE), ONERA CFM

${ }^{5}$ Head of Propulsion Laboratory Research Unit, Multi-Physic for Energetics Department (DMPE), ONERA CFM, AIAA Senior Member
} 


\section{Pre-screening of catalysts prepared with various precious metals}

\section{A. Preparation of the catalysts}

All the catalysts tested in the context of the present work were prepared by means of a conventional incipient wetness impregnation. The water uptake of the alumina carriers was measured, and the concentration of the various precious metal's impregnation solutions were then adjusted to reach the targeted precious metal loading of 5\% on the catalysts. After impregnation, the obtained catalysts were dried, calcined and reduced. Table 1 below presents the catalysts prepared for the pre-screening. The various precious metals $(\mathrm{Pt}, \mathrm{Pd}, \mathrm{Rh}, \mathrm{Ir}$ and $\mathrm{Ag}$ ) were supported on the flight proven $\gamma$-alumina granules used to produce the hydrazine decomposition catalyst $\mathrm{HKC}-12 \mathrm{GA}\left(\mathrm{Al}_{2} \mathrm{O}_{3}-1\right)$. A grain size fraction between 18 and 20 mesh was selected for the preparation of the catalytic systems and kept constant for all the catalysts as this parameter can have a huge impact on the catalytic activity.

\section{Table 1 Catalytic systems prepared for the pre-screening}

\begin{tabular}{|c|c|}
\hline Catalyst & Pt content (\%) \\
\hline $\mathrm{Pt} / \mathrm{Al}_{2} \mathrm{O}_{3}-1-18-20$ mesh & 5 \\
\hline $\mathrm{Pd} / \mathrm{Al}_{2} \mathrm{O}_{3}-1-18-20$ mesh & 5 \\
\hline $\mathrm{Rh} / \mathrm{Al}_{2} \mathrm{O}_{3}-1-18-20$ mesh & 5 \\
\hline $\mathrm{Ir} / \mathrm{Al}_{2} \mathrm{O}_{3}-1-18-20$ mesh & 5 \\
\hline $\mathrm{Ag} / \mathrm{Al}_{2} \mathrm{O}_{3}-1-18-20$ mesh & 5 \\
\hline
\end{tabular}

\section{B. Laboratory apparatus and test procedure}

The catalysts were tested in a simple laboratory apparatus composed of a flask, a syringe to introduce $\mathrm{H}_{2} \mathrm{O}_{2}$ and a graduated cylinder to measure the volume of the released hot gas mixture (Fig. 1). Before the test, each catalyst was dried in an infra-red moisture analyzer and $200 \mathrm{mg}$ of solid are introduced in the reaction flask. Next, $1 \mathrm{~mL}$ of $\mathrm{H}_{2} \mathrm{O}_{2}$ (30\% solution from Merck) solution is added to the catalyst with the syringe and the volume of the released hot gas mixture was measured as well as the decomposition time.

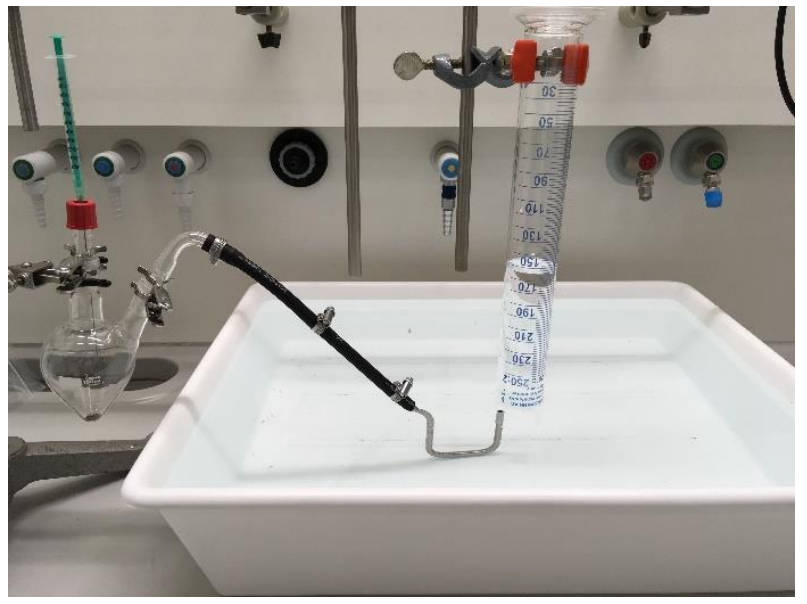

Fig. 1 Laboratory apparatus for $\mathrm{H}_{2} \mathrm{O}_{2}$ decomposition

\section{Results of the pre-screening}

Each catalyst was tested three times and Fig. 2 below presents the average decomposition time measured for each catalyst. The Rh-based catalyst shows the lowest activity with a decomposition of 20,9s. Moreover, with this catalyst, $\mathrm{H}_{2} \mathrm{O}_{2}$ is not fully decomposed and a volume of hot gases of $75 \mathrm{~mL}$ was measured which is about half of the expected gas release based on the decomposition of $1 \mathrm{~mL}$ of the $30 \% \mathrm{H}_{2} \mathrm{O}_{2}$ solution. On the other hand, the other catalysts tested for this pre-screening were all able to fully decompose $\mathrm{H}_{2} \mathrm{O}_{2}$ and a volume of about $150 \mathrm{~mL}$ of hot gases was measured. As can be seen from Fig. 2 below, Pt shows the shortest decomposition time followed by Ir, $\mathrm{Ag}$, Pd and Rh. Pt and Ir showed similar activity with decomposition times of respectively 1,8s and 2,1s. Many 
different precursors of Pt are available by Heraeus which might have an big impact on the catalytic activity and Pt was therefore selected for the fine screening presented below.

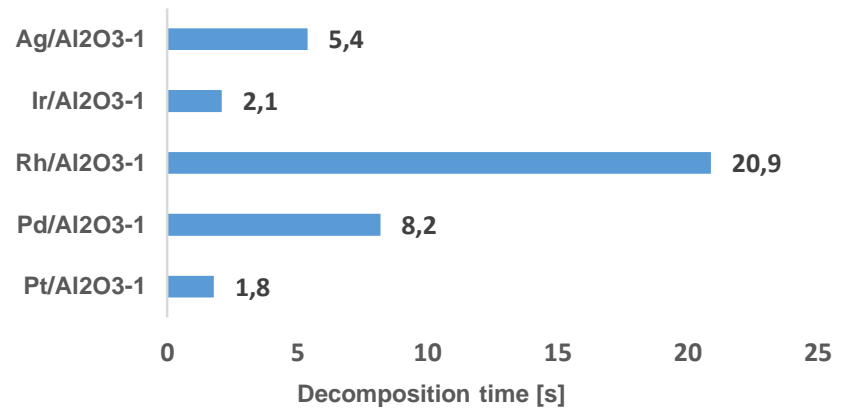

Fig. 2 Decomposition times measured during the pre-screening

\section{Fine screening of Pt catalysts}

\section{A. Preparation of the catalysts and testing}

The aim of this fine screening was to investigate the influence of some preparation parameters on the catalytic activity of the $\mathrm{Pt} / \mathrm{Al}_{2} \mathrm{O}_{3}$ system. Three different Pt precursors (A, B and C) were used to prepare the catalysts and two different carriers were also studied, namely the $\gamma$-alumina granules used to produce the hydrazine decomposition catalyst HKC-12GA $\left(\mathrm{Al}_{2} \mathrm{O}_{3}-1\right)$ and an alternative $\gamma$-alumina granules $\left(\mathrm{Al}_{2} \mathrm{O}_{3}-2\right)$. The choice of $\gamma$-alumina is critical for this kind of catalytic bed as it was already shown in the past that $\gamma$-alumina supported catalyst tend to crack when brought in contact with highly concentrated $\mathrm{H}_{2} \mathrm{O}_{2}$ solutions [11-12]. The size of the granules was again the fraction between 18 mesh and 20 mesh. The catalytic systems tested during this fine screening are listed in Table 2 below. These catalysts were prepared using the same incipient wetness impregnation method as the one used for the prescreening and the Pt loading was again kept constant and equal to 5\%. The first tests for the fine screening were performed with the $30 \% \mathrm{H}_{2} \mathrm{O}_{2}$ solution, but with this concentration no difference could be observed between all the very active Pt systems and the concentration had to be decreased down to $10 \%$ to better investigate the impact of the studied parameters on the catalytic activity.

Table 2 Catalytic systems prepared for the fine screening

\begin{tabular}{|c|c|}
\hline Catalyst & Pt content (\%) \\
\hline $\mathrm{Pt}(\mathrm{A}) / \mathrm{Al}_{2} \mathrm{O}_{3}-1-18-20$ mesh & 5 \\
\hline $\mathrm{Pt}(\mathrm{B}) / \mathrm{Al}_{2} \mathrm{O}_{3}-1-18-20$ mesh & 5 \\
\hline $\mathrm{Pt}(\mathrm{C}) / \mathrm{Al}_{2} \mathrm{O}_{3}-1-18-20$ mesh & 5 \\
\hline $\mathrm{Pt}(\mathrm{C}) / \mathrm{Al}_{2} \mathrm{O}_{3}-2-18-20$ mesh & 5 \\
\hline
\end{tabular}

\section{B. Characterization of the catalysts}

Characterization of the catalysts consisted of determination of the precious metal surface by $\mathrm{CO}$-adsorption, determination of the pore volume by Hg-porosimetry, scanning electron microscopy coupled with energy dispersive $\mathrm{X}$-ray spectroscopy (SEM-EDX) and transmission electron microscopy (TEM).

The precious metal surface area tests were performed in a TPDRO 1100 device from the Thermo Finnigan Company. Before testing, the catalysts are reduced for $2 \mathrm{~h}$ in a reductive gas mixture $\left(95 \% \mathrm{Ar}, 5 \% \mathrm{H}_{2}\right)$.

The Hg-porosimetry analysis were conducted using two devices namely a Pacal P140 and a Pascal P440 from the company Thermo Fischer Scientific. Before testing, the samples are degassed at $150^{\circ} \mathrm{C}$ for $12 \mathrm{~h}$.

The SEM-EDX analyses were performed using the Scanning Electron Microscope Jeol JSM-IT100 equipped with integrated energy dispersive X-ray analysis system, using a 20 keVelectron beam. The depth penetration for 20 $\mathrm{keV}$ incident electrons is about $1 \mu \mathrm{m}$; therefore, SEM-EDX provides quantitative analysis of elemental composition of the specimen surface with a sampling depth of $1 \mu \mathrm{m}$. The methodology of investigation used is the following: one layer of pellets for each catalyst sample were embedded in resin, cross-sectioned in half and polished. In the SEM a BSE-picture (backscattered electrons) in minimum magnification was used to pick some characteristic/ representative pellets. 
TEM investigations were conducted using a FEI Talos 20-200 transmission microscope at $200 \mathrm{kV}$. The measurements were performed in TEM mode and in STEM using Bright Field (BF) imaging and HAADF detector. Energy-dispersive x-ray spectroscopy was used to detect differences in local chemical composition.

\section{Results of the fine screening and discussion}

The decomposition times for the four catalysts are presented in Fig. 3 below. As expected, the decomposition times measured with the diluted $\mathrm{H}_{2} \mathrm{O}_{2}$ solution are much longer and allowed us a better discrimination of the catalytic systems. We observed full decomposition of the hydrogen peroxide and a volume of hot gases of $50 \mathrm{~mL}$ was measured, which corresponds to the volume expected for the decomposition of $1 \mathrm{~mL}$ of a $10 \% \mathrm{H}_{2} \mathrm{O}_{2}$ solution.

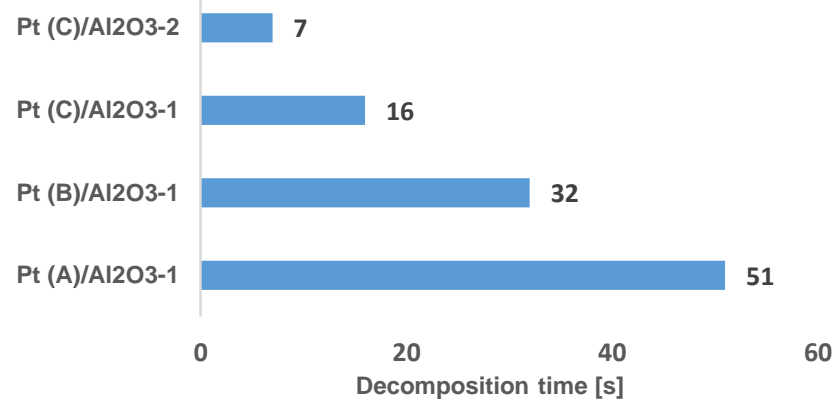

Fig. 3 Decomposition times measured during the fine screening

Among the three Pt precursors used for the preparation of the catalysts tested during this fine screening, Pt salt A shows the lowest activity with a decomposition time of 51s. This is about two times, respectively three times longer than the decomposition times observed for the catalyst prepared with precursor B and C. The SEM images of these three catalysts are presented in Fig. 4 below. As can be seen from these images, precursors A tends to travel much deeper in the alumina pores compared to precursors $\mathrm{B}$ and $\mathrm{C}$ and the alumina granules prepared with this salt are almost homogeneously impregnated. On the other side, in the catalysts prepared with precursors $\mathrm{B}$ and $\mathrm{C}, \mathrm{Pt}$ tends to stay at the surface of the alumina granules and these catalysts present an egg-shell profile with much higher local concentrations of $\mathrm{Pt}$ at the surface of the granules. This higher concentration of $\mathrm{Pt}$ at the surface of the granules explains the higher activity for the decomposition of $\mathrm{H}_{2} \mathrm{O}_{2}$, which does not have to enter deeply the pores of the catalyst to react on the active sites.
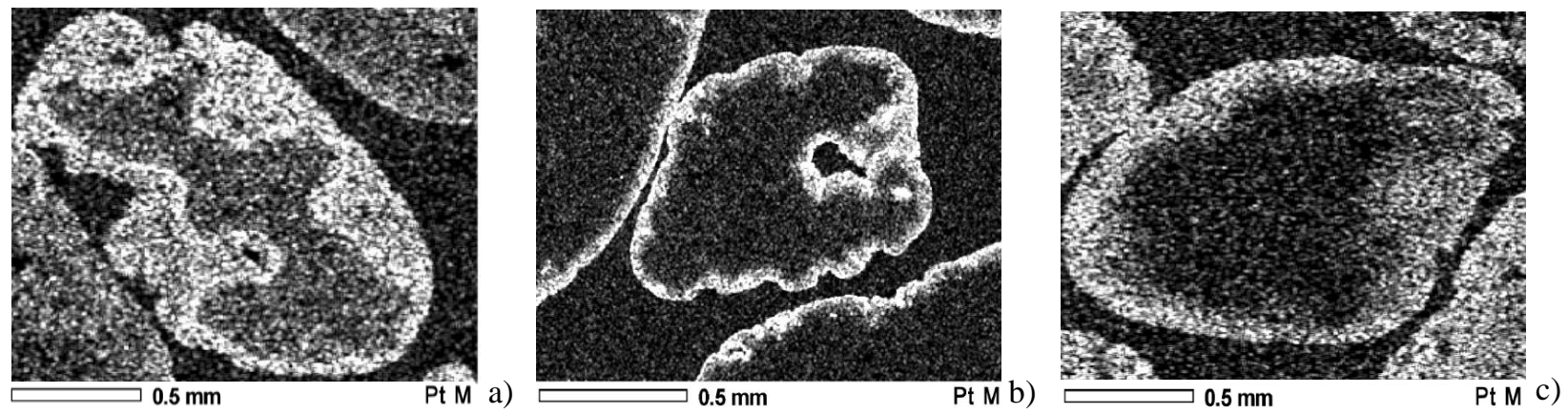

Fig. 4 SEM images of a) $\mathrm{Pt}(\mathrm{A}) / \mathrm{Al}_{2} \mathrm{O}_{3}-1$, b) $\mathrm{Pt}(\mathrm{B}) / \mathrm{Al}_{2} \mathrm{O}_{3}-1$, c) $\mathrm{Pt}(\mathrm{C}) / \mathrm{Al}_{2} \mathrm{O}_{3}-1$

As can be seen from image b) and c), the egg-shell profile for the catalyst prepared with precursor $B$ is sharper than the one observed for catalyst prepared with precursor $\mathrm{C}$ and a rough estimation of the shell thickness showed that the shell observed for precursor B is about two time thinner than for precursor C (respectively $50 \mu \mathrm{m}$ and $100 \mu \mathrm{m}$ ). Nevertheless, catalyst prepared with precursor $\mathrm{C}$ shows the highest activity with a decomposition time about two times shorter than catalyst prepared with precursor B. The TEM images as well as the crystallite size distribution for the catalysts prepared with precursors B and C are presented in Fig. 5 and Fig. 6 below.

As can be seen in the TEM images, the Pt nanoparticles obtained with precursor $\mathrm{C}$ are much smaller than the ones observed for the catalyst prepared with precursor $\mathrm{B}$. This observation is confirmed by the crystallite size distribution presented in Fig. 6. For the catalyst $\mathrm{Pt}(\mathrm{B}) / \mathrm{Al}_{2} \mathrm{O}_{3}-1$, a very broad distribution is obtained and most of the particles 
have a diameter comprised between $10 \mathrm{~nm}$ and $30 \mathrm{~nm}$. On the other hand, a very narrow distribution is observed for catalyst $\mathrm{Pt}(\mathrm{C}) / \mathrm{Al}_{2} \mathrm{O}_{3}-1$ and most of the nanoparticles of Pt have a diameter comprised between $1 \mathrm{~nm}$ and $4 \mathrm{~nm}$.

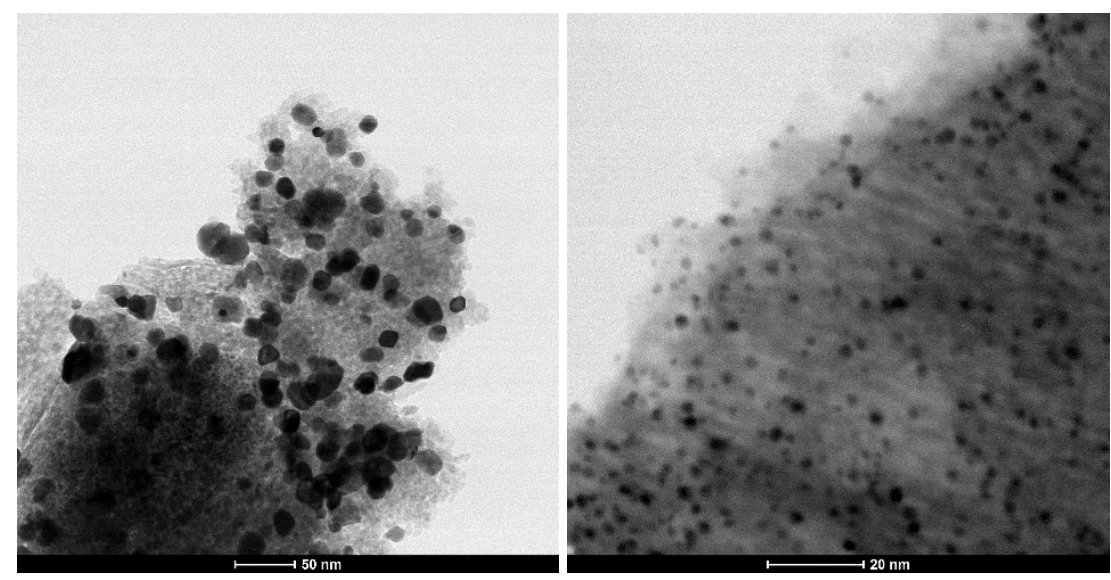

Fig. 5 TEM images of $\mathrm{Pt}(\mathrm{B}) / \mathrm{Al}_{2} \mathrm{O}_{3}-1$ (left) and $\mathrm{Pt}(\mathrm{C}) / \mathrm{Al}_{2} \mathrm{O}_{3}-1$ (right)
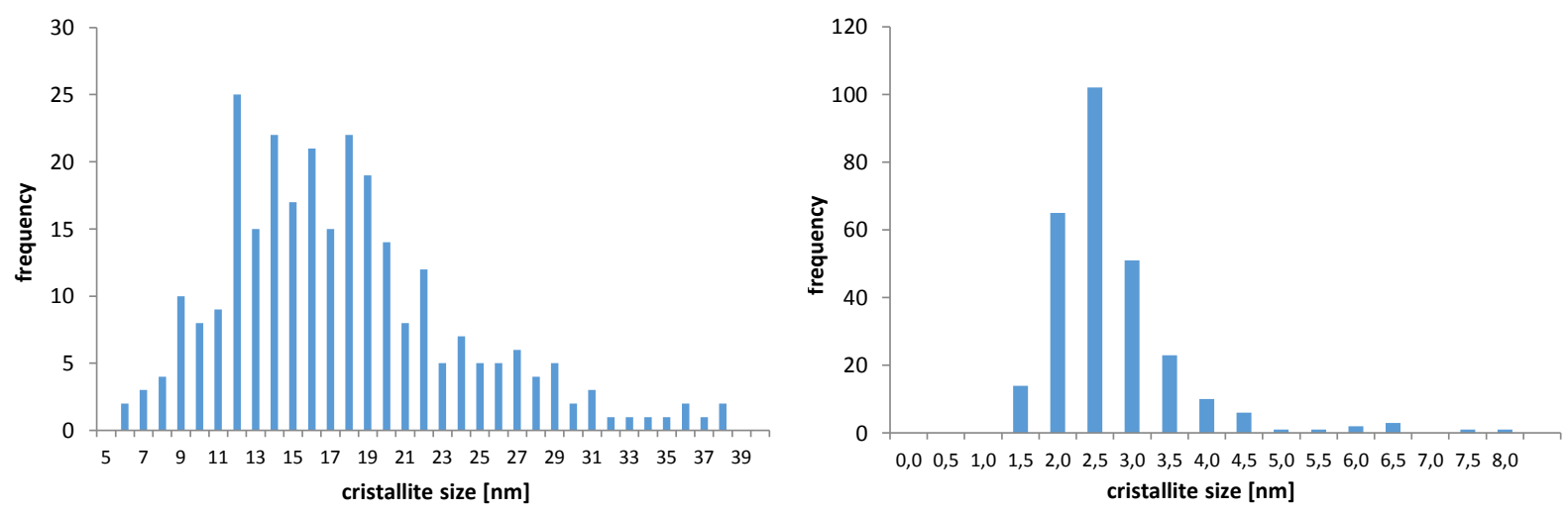

Fig. 6 Crystallite size distribution for catalysts $\mathrm{Pt}(\mathrm{B}) / \mathrm{Al}_{2} \mathrm{O}_{3}-1$ (left) and $\mathrm{Pt}(\mathrm{C}) / \mathrm{Al}_{2} \mathrm{O}_{3}-1$ (right)

This much smaller particle size, i.e. much better dispersion of the Pt observed with precursor $\mathrm{C}$ explains the higher catalytic activity observed for this catalyst compared to the catalyst impregnated with precursor B. This better dispersion was also confirmed by the metallic surface areas determined with the $\mathrm{CO}$ adsorption measurements presented in Table 3 below. The catalyst prepared with Pt salt $\mathrm{C}$ shows a metallic surface area about five time bigger than the one measured for precursor B.

Table 3 Metallic surface area measured for $\mathrm{Pt}(\mathrm{B}) / \mathrm{Al}_{2} \mathrm{O}_{3}-1$ and $\mathrm{Pt}(\mathrm{C}) / \mathrm{Al}_{2} \mathrm{O}_{3}-1$

\begin{tabular}{|c|c|}
\hline Catalyst & Metallic surface area $\left(\mathbf{m}^{2} / \mathbf{g}\right)$ \\
\hline $\mathrm{Pt}(\mathrm{B}) / \mathrm{Al}_{2} \mathrm{O}_{3}-1-18-20$ mesh & 2,1 \\
\hline $\mathrm{Pt}(\mathrm{C}) / \mathrm{Al}_{2} \mathrm{O}_{3}-1-18-20$ mesh & 11,0 \\
\hline
\end{tabular}

The Pt precursor $\mathrm{C}$ shows the highest activity among the three precursors tested during the fine screening. This precursor was therefore selected to prepare one additional catalyst supported on an alternative $\gamma$-alumina, namely $\mathrm{Al}_{2} \mathrm{O}_{3}-2$. This additional catalyst shows improved catalytic activity compared to the one prepared on the conventional alumina, with a decomposition time about two time shorter. The various characterizations performed on this additional catalyst are presented in Fig. 7 below. The results obtained for the catalyst supported on the alternative alumina are very similar to the one observed for the material impregnated on the standard alumina $\mathrm{Al}_{2} \mathrm{O}_{3^{-}}$ 1. The SEM image presented in Fig. 7 below shows a relatively sharp egg-shell profile with a shell-thickness of about $130 \mu \mathrm{m}$. The TEM investigations also shows very similar results as the ones observed for the standard 
alumina. Some very small Pt nanoparticle can be observed on the TEM image below and the crystallite size distribution shows a very narrow distribution with most of the particles having a size comprised between $1 \mathrm{~nm}$ and 3 $\mathrm{nm}$. These nanoparticles are slightly smaller than the one observed for the catalyst prepared on the conventional alumina, which might partially explain why this catalyst shows a better catalytic activity during the $\mathrm{H}_{2} \mathrm{O}_{2}$ decomposition test performed in the laboratory apparatus.
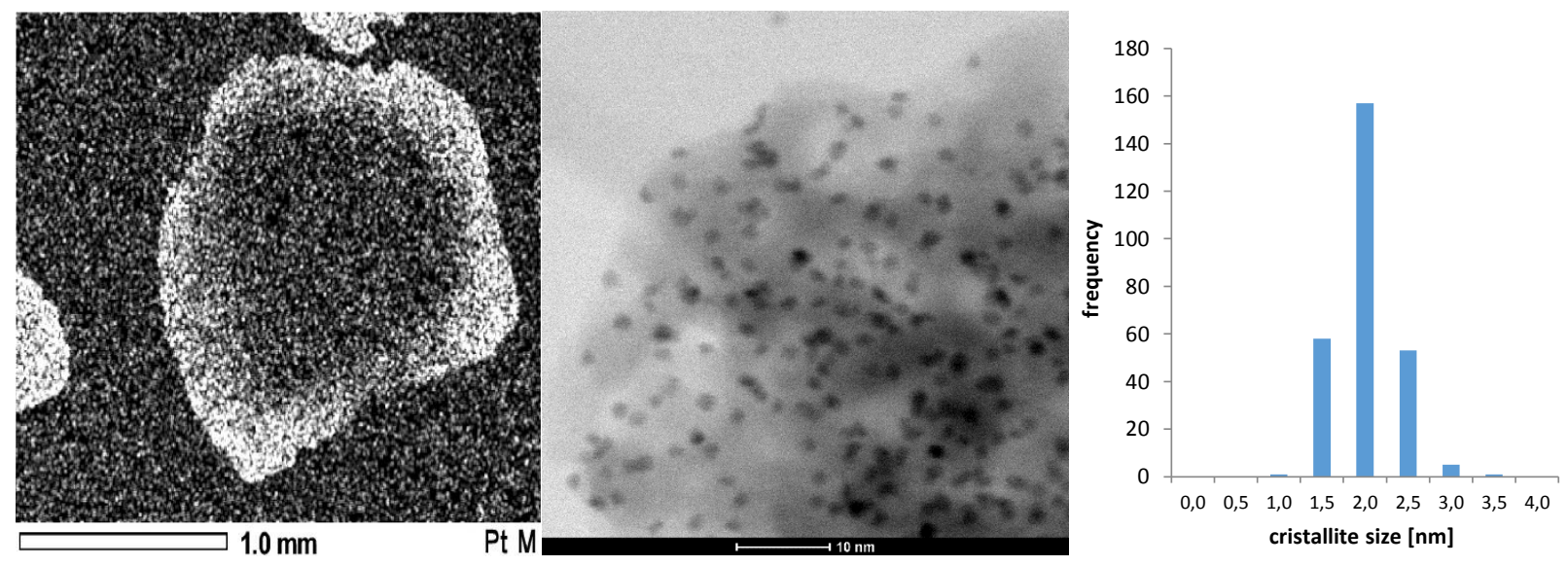

Fig. 7 SEM (left), TEM (middle) images and crystallite size distribution (left) for the catalyst $\mathrm{Pt}(\mathrm{C}) / \mathrm{Al}_{2} \mathrm{O}_{3}-2$

An additional explanation for this improved activity can be the differences observed in the pore volume and the pore diameter distribution presented in Table 4 and Fig. 8 below. The catalyst supported on the alternative alumina $\mathrm{Al}_{2} \mathrm{O}_{3}$-2 shows a total pore volume about two times bigger than the conventional alumina granules. Moreover, the pores size distribution presented in Fig. 8 below shows that the highest contribution to the total pore volume comes from the pores with a diameter between $3 \mathrm{~nm}$ and $5 \mathrm{~nm}$ for $\mathrm{Al}_{2} \mathrm{O}_{3}-1$, whereas the highest contribution to the total pore volume for $\mathrm{Al}_{2} \mathrm{O}_{3}-2$ comes from the pores having a diameter comprised between $5 \mathrm{~nm}$ and $10 \mathrm{~nm}$. These differences in the micropores distribution might explain the better activity observed for the catalyst supported on the alternative alumina and further investigations are needed to better understand the influence of this parameter on the catalytic activity.

Table 4 Pore volume and average pore diameter for catalyst $\mathrm{Pt}(\mathrm{C}) / \mathrm{Al}_{2} \mathrm{O}_{3}-1$ and $\mathrm{Pt}(\mathrm{C}) / \mathrm{Al}_{2} \mathrm{O}_{3}-2$

\begin{tabular}{|c|c|c|}
\hline Catalyst & Pore volume $\left(\mathbf{c m}^{3} / \mathbf{g}\right)$ & Average pore diameter $(\mathbf{n m})$ \\
\hline $\mathrm{Pt}(\mathrm{C}) / \mathrm{Al}_{2} \mathrm{O}_{3}-1-18-20$ mesh & 0,16 & 10,03 \\
\hline $\mathrm{Pt}(\mathrm{C}) / \mathrm{Al}_{2} \mathrm{O}_{3}-2-18-20 \mathrm{mesh}$ & 0,30 & 13,57 \\
\hline
\end{tabular}
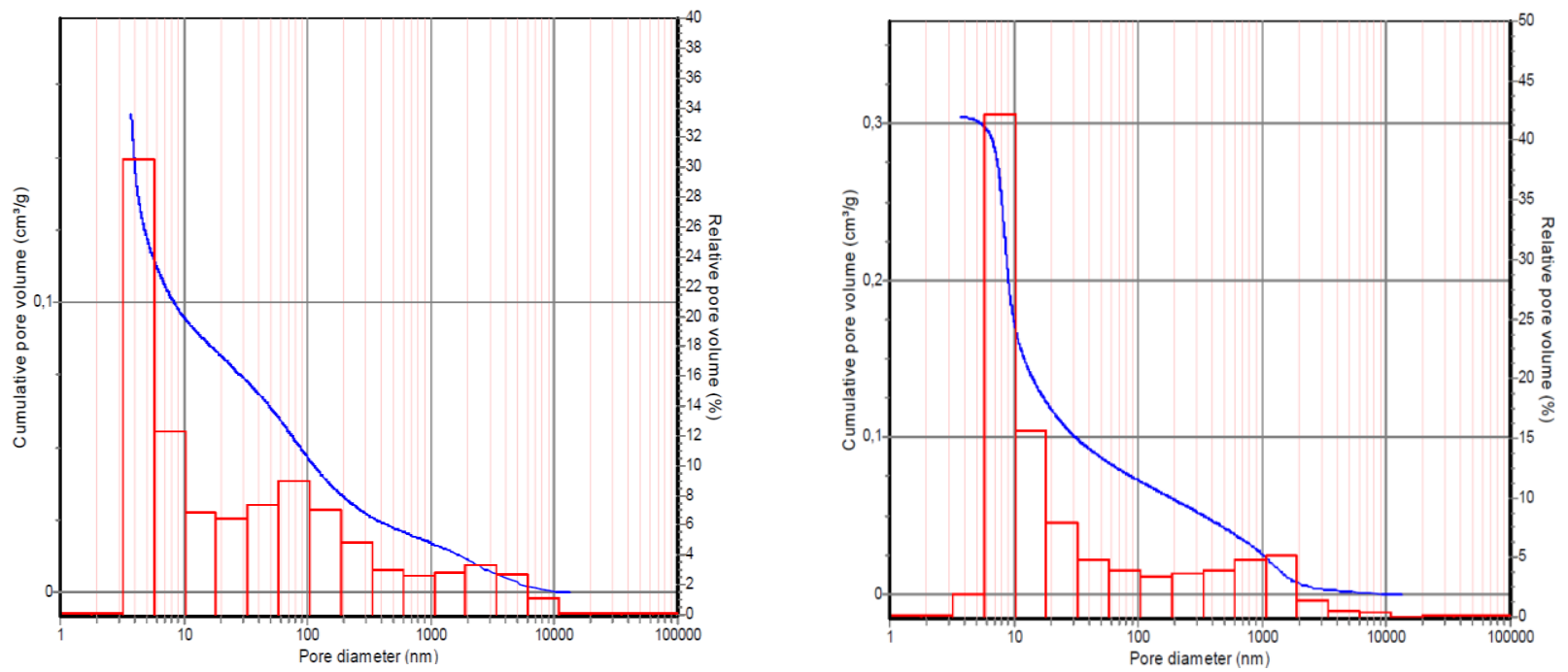
Fig. 8 Pore size distribution for catalysts $\mathrm{Pt}(\mathrm{C}) / \mathrm{Al}_{2} \mathrm{O}_{3}-1$ (left) and $\mathrm{Pt}(\mathrm{C}) / \mathrm{Al}_{2} \mathrm{O}_{3}-2$ (right)

\section{Monopropellant test campaign}

\section{A. Catalysts selected for the campaign}

Four catalysts (A, B, C and D) were prepared for the test campaign performed by ONERA in their monopropellant test facility. The catalysts listed in Table 5 were prepared with the Pt-precursor $\mathrm{C}$, which showed the most promising results during the laboratory screening. Catalyst $\mathrm{A}, \mathrm{B}$ and $\mathrm{C}$ were prepared with three different granules sizes of the $\mathrm{Al}_{2} \mathrm{O}_{3}-1$ alumina. Catalyst $\mathrm{D}$ was prepared with the alternative $\gamma$-alumina $\mathrm{Al}_{2} \mathrm{O}_{3}-2$ described before and with the same granules size as the one used to produce catalyst A. The Pt content was again kept constant and equal to $5 \%$.

Table 5 Catalysts for the monopropellant test campaign

\begin{tabular}{|c|c|}
\hline Catalyst & Pt content (\%) \\
\hline $\mathrm{A}-\mathrm{Pt}(\mathrm{C}) / \mathrm{Al}_{2} \mathrm{O}_{3}-1-10-14$ mesh & 5 \\
\hline $\mathrm{B}-\mathrm{Pt}(\mathrm{C}) / \mathrm{Al}_{2} \mathrm{O}_{3}-1-18-20$ mesh & 5 \\
\hline $\mathrm{C}-\mathrm{Pt}(\mathrm{C}) / \mathrm{Al}_{2} \mathrm{O}_{3}-1-20-25$ mesh & 5 \\
\hline $\mathrm{D}-\mathrm{Pt}(\mathrm{C}) / \mathrm{Al}_{2} \mathrm{O}_{3}-2-10-14$ mesh & 5 \\
\hline
\end{tabular}

\section{B. Description of the monopropellant test facility}

The monopropellant test facility consists basically of the three following main components: the inlet manifold connected to the hydrogen peroxide feed line, an injector plate and the decomposition chamber containing the catalyst particles (Fig. 9). The injector plate was especially designed to spread the liquid hydrogen peroxide all over the cross section of the decomposition chamber. This chamber consists of an Inconel cylinder closed at both ends by refractory steel meshes to maintain the catalyst particles inside the decomposition chamber.

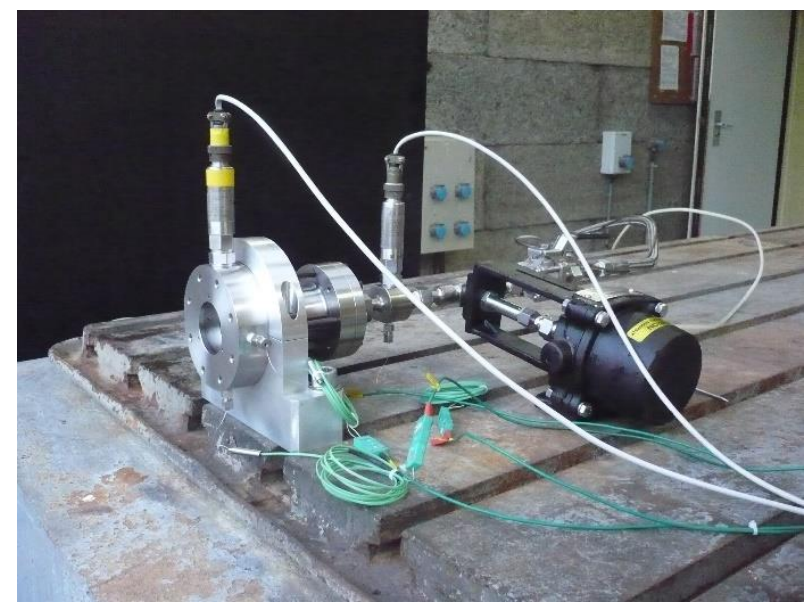

Fig. 9 Monopropellant test facility

This chamber is connected to a measurement module measuring the decomposition temperature at the outlet of the catalytic bed thanks to three thermocouples and the decomposition chamber pressure. The instrumentation of this facility also includes a Coriolis oxidizer mass flow measurement and temperature and pressure measurements of the liquid oxidizer upstream the manifold.

\section{Test results}

For this test campaign, each test was performed during $10 \mathrm{~s}$ and the oxidizer mass flow rate was kept constant and equal to $90 \mathrm{~g} / \mathrm{s}$. Indeed, it was important to keep this parameter constant to get a direct comparison between the four different catalysts since the transient phase duration depends on the oxidizer mass flow rate. A lower oxidizer mass flow rate leads to a higher transient phase duration and vice-versa. 
Thanks to a constant tank pressure during the monopropellant test, the oxidizer mass flow rate is stable during the second part of the test due to steady temperature at the outside of the decomposition chamber (Fig. 10). During the first part of this test (up to $5 \mathrm{~s}$ ), the decomposition temperature increases continuously which leads to a slight decrease of the oxidizer mass flow rate. Before going up to about $910 \mathrm{~K}$, the decomposition temperature shows a short plateau at temperature of about $360 \mathrm{~K}$ which corresponds to the water decomposition temperature.

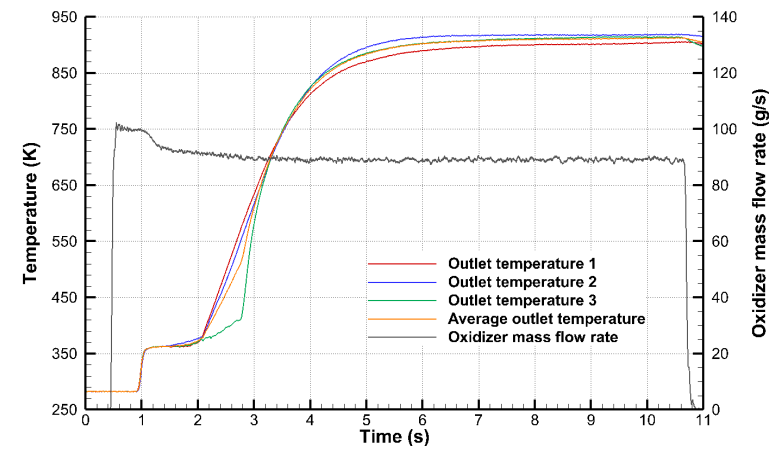

\section{Fig. 10 Results of a test performed with the catalyst sample A}

Figure 11 below presents the decomposition temperature in the chamber, which was normalized according to Eq.1.

$$
T_{\text {norm }}=\frac{T_{d e c}-T_{i n j}}{T_{a d}-T_{i n j}}
$$

With $T_{\text {norm }}$ the normalized temperature, $T_{\text {dec }}$ the measured decomposition temperature, $T_{\text {inj }}$ the injection temperature of the liquid oxidizer and $\mathrm{T}_{\mathrm{ad}}$ the adiabatic decomposition temperature, which was obtained thanks to a thermochemical equilibrium code. This equation was used to overcome the variations in the injection temperature as well as the variation observed in the hydrogen peroxide concentration from test to test.

Before comparing the activity of the catalysts, each sample was submitted to four consecutives monopropellant tests to insure a good reproducibility of the results. The temperature evolution for the four tests performed on catalyst C are presented in Fig. 11 below. As can be seen from this figure, the temperature evolution for the last three monopropellant tests match well and an efficiency of $97.4 \%$ was reached based on the normalized temperature.

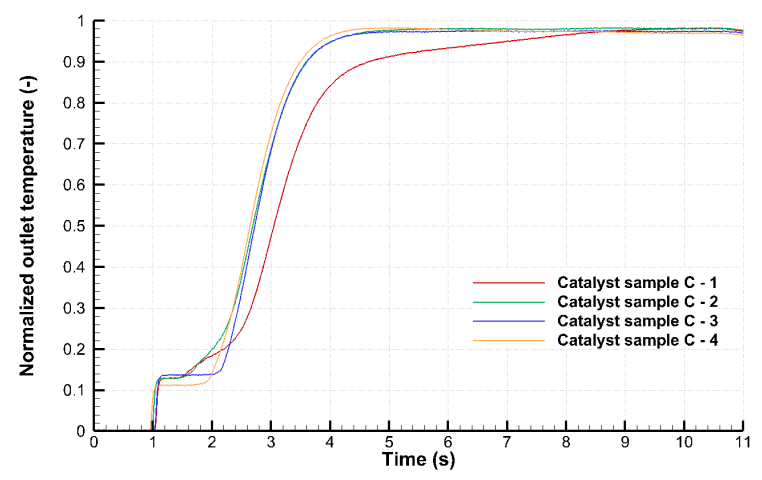

Fig. 11 Decomposition temperature evolution of catalyst sample $\mathbf{C}$ for the four tests

Finally, the normalized temperatures for the four catalyst samples are presented and compared in Fig. 12 below. First, the comparison between catalyst A, B and C shows that the smallest the particle size, the shorter the transient time and the higher the efficiency based on the normalized temperature. On the other hand, catalyst $\mathrm{D}$, which was prepared with the same particle size as catalyst $A$ but with the alternative alumina $\mathrm{Al}_{2} \mathrm{O}_{3}-2$, shows improved efficiency as well as a shorter transient phase duration. These results confirm the better catalytic activity of the catalyst supported on $\mathrm{Al}_{2} \mathrm{O}_{3}-2$, which was already observed during the laboratory screening. 


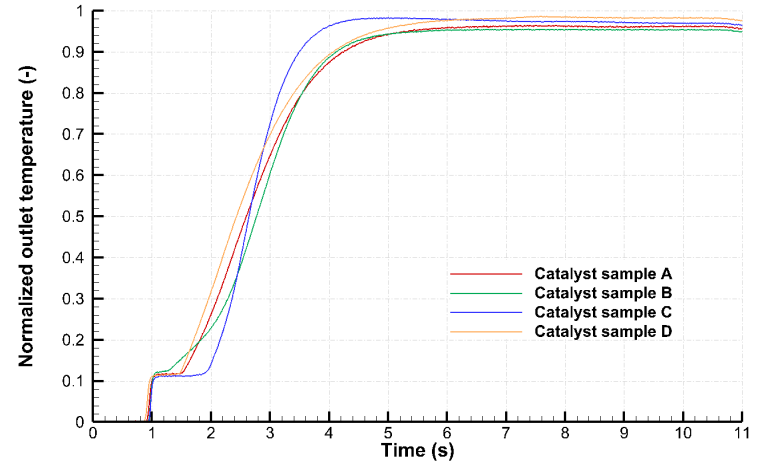

Fig. 12 Comparison between the decomposition temperatures of the four catalyst samples

The final choice for the best catalytic system was finally made between catalyst $\mathrm{C}$ and $\mathrm{D}$. On the one hand shows catalyst $\mathrm{C}$ a shorter transient time $(2.5 \mathrm{~s}$ against $3.2 \mathrm{~s})$. On the other hand, catalyst $\mathrm{D}$ supported on the alternative alumina granules shows improved efficiency compared to catalyst C (respectively $98.5 \%$ and $97.4 \%$ ). Moreover, the post-test analysis of the catalytic bed prepared with sample $\mathrm{C}$ showed the tendency of these very fine particles to aggregation and some bigger particles were observed. This aggregation could have a negative impact on the performances of the catalyst bed during longer cumulative test durations and consequently catalyst sample D was selected for the hybrid firing test campaigns reported in Ref. 13 and Ref. 14.

\section{Conclusion}

A reliable and effective catalytic bed is one of the key elements for the development of a highly concentrated hydrogen peroxide thruster. A pre-screening performed at Heraeus in a very simple laboratory apparatus on various precious metals supported on the flight proven $\gamma$-alumina granules used to produce the hydrazine decomposition catalyst $\mathrm{HKC}-12 \mathrm{GA}\left(\mathrm{Al}_{2} \mathrm{O}_{3}-1\right)$ showed that $\mathrm{Pt}$ is the most active precious metal for the catalytic decomposition of $\mathrm{H}_{2} \mathrm{O}_{2}$. A more detailled screening was then performed on several $\mathrm{Pt}$ catalysts prepared with three different $\mathrm{Pt}$ precursors as well as two different aluminas. These catalysts were fully characterized using various techniques like SEM-EDX, TEM and Hg-porosimetry. The most effective combination was found to be $\mathrm{Pt}(\mathrm{C}) / \mathrm{Al}_{2} \mathrm{O}_{3}-2$. This catalyst shows the highest Pt dispersion, with nanoparticles of about $2 \mathrm{~nm}$ as well as a good egg-shell profile. The monopropellant test campaign performed by ONERA on four Pt catalysts confirmed the better activity of this catalytic system under real conditions $\left(87,5 \% \mathrm{H}_{2} \mathrm{O}_{2}\right)$. Surprisingly, the several hot-firing tests performed on this catalytic system did not show a noticeable ageing of the catalyst and the decomposition activity of the catalyst remained almost unchanged after the exposition to several kilograms of highly concentrated hydrogen peroxide. A post-test characterization of the catalyst would be necessary to further understand the ageing behavior of this catalytic system during the hot-firing tests.

\section{References}

[1] Gohardani, A. S., Stanojev, J., Demairé, A., Anflo, K., Persson, M., Wingborg, N., and Nilsson, C., "Green Space Propulsion: Opportunities and Prospects," Progress in Aerospace Sciences, Vol. 71, Nov. 2014, pp. 128-149.

doi: 10.1016/j.paerosci.2014.08.001

[2] Masse, M., Allen, M., Spores, R., and Driscoll, A. A., “AF-M315E Propulsion System Advances and Improvements," 52nd AIAA/SAE/ ASEE Joint Propulsion Conference, AIAA Propulsion and Energy Forum, AIAA Paper 2016-4577, 2016. doi:10.2514/6.2016-4577

[3] Dolci, S., Belli Dell'Amico, D., Pasini, A., Torre, L., Pace, G., and Valentini, D., "Platinum Catalysts Development for 98\% Hydrogen Peroxide Decomposition in Pulsed Monopropellant Thrusters," Journal of Propulsion and Power, Vol. 31, No. 4, 2015, pp. 1204-1216. doi:10.2514/1.B35590

[4] Torre, L., Pasini, A., Romeo, L., Cervone, A., and d'Agostino, L., "Performance of a Monopropellant Thruster Prototype Using Advanced Hydrogen Peroxide Catalytic Beds," Journal of Propulsion and Power, Vol. 25, No. 6, 2009, pp. 1291-1299. doi:10.2514/1.44354 
[5] Koopmans, R. J., Shrimpton, J. S., Roberts, G. T., and Musker, A. J., “A One-Dimensional Multicomponent Two-Fluid Model of a Reacting Packed Bed Including Mass, Momentum and Energy Interphase Transfer," International Journal of Multiphase Flow,Vol. 57, Dec. 2013, pp. 10-28.

doi:10.1016/j.ijmultiphaseflow.2013.06.005

[6] Maia, F. F., Gouvea, L. H., Pereira, L. G. F., Vieira, R., and De Souza Costa, F., "Development and Optimization of a Catalytic Thruster for Hydrogen Peroxide Decomposition," Journal of Aerospace Technology and Management, Vol. 6, No. 1, 2014, pp. 61-67. doi:10.5028/jatm.v6i1.286

[7] Bonifacio, S., Russo Sorge, A., Krejci, D., Woschnak, A., and Scharlemann, C., "Novel Manufacturing Method for Hydrogen Peroxide Catalysts:APerformanceVerification," Journal of Propulsion and Power, Vol. 30, No. 2, 2014, pp. $299-308$. doi:10.2514/1.B34959

[8] Pirault-Roy, L., Kappenstein, C., Guerin, M., Eloirdi, R., and Pillet, N., "Hydrogen Peroxide Decomposition on Various Supported Catalysts Effect of Stabilizers," Journal of Propulsion and Power, Vol. 18, No. 6, 2002, pp. 1235-1241. doi:10.2514/2.6058

[9] Rusek, J. J., "New Decomposition Catalysts and Characterization Techniques for Rocket-Grade Hydrogen Peroxide," Journal of Propulsion and Power, Vol. 12, No. 3, 1996, pp. 574-579.

doi: $10.2514 / 3.24071$

[10] Romeo, L., Torre, L., Pasini, A., Cervone, A., and d'Agostino, L., "Performance of Different Catalysts Supported on Alumina Spheres for Hydrogen Peroxide Decomposition," 43rd AIAA/ASME/SAE/ ASEE Joint Propulsion Conference \& Exhibit, AIAA Paper 2007- 5466, 2007. doi:10.2514/6.2007-5466

[11] Surmacz, P., "Influence of Various Types of $\mathrm{Al}_{2} \mathrm{O}_{3} \mathrm{Mn}_{\mathrm{x}} \mathrm{O}_{\mathrm{y}}$ Catalysts on Performance of a $100 \mathrm{MM}$ Chamber for Decomposition of 98\%+ Hydrogen Peroxide," Transaction of the Institute of Aviation, Vol. 240, No. 3, 2015 , pp. 58-68. doi:10.5604/05096669.1194986

[12] Pasini, A., Torre, L., Romeo, L., Cervone, A., and d'Agostino, L., "Testing and Characterization of a Hydrogen Peroxide Monopropellant Thruster," Journal of Propulsion and Power, Vol. 24, No. 3, 2008, pp. 507-515. doi:10.2514/1.33121

[13] Lestrade, J.Y., Prévot, P., Messineo, J., Anthoine, J., Casu, S. and Geiger, B., "Development of a Catalyst for High Concentrated Hydrogen peroxide," $6^{\text {th }}$ International Symposium on Propulsion for Space Transportation (Space Propulsion), Roma, Italy, May 2016.

[14] Anthoine, J., Lestrade, J.Y., Messineo, J. and Casu, S., "Performances of a Multi-Pulsed Hybrid Rocket Engine Operating with Highly Concentrated Hydrogen Peroxide", 53 ${ }^{\text {rd }}$ AIAA/SAE/ASEE Joint Propulsion Conference, Atlanta, USA, July 2017 